\section{Tercio Creciente}

DOI: https://dx.doi.org/10.17561/rtc.20.6011 Investigación
Maneras de habitar los espacios desde la mirada estética Julio 2021

\section{La corriente del Postdegrado. Análisis y recopilación de buenas prácticas de regeneración socio-cultural en espacios abandonados}

\section{The Postdegrado movement. Analysis and review of best practices related to socio-cultural regeneration in abandoned areas}

Sugerencias para citar este artículo:

Degradi, Ilaria (2021). La corriente del Postdegrado. Análisis y recopilación de buenas prácticas de regeneración socio-cultural en espacios abandonados. Tercio Creciente 20, (pp. 137-144), https://dx.doi.org/10.17561/rtc.20.6011

DEGRADI, ILARIA. La corriente del Postdegrado. Análisis y recopilación de buenas prácticas de regeneración socio-cultural en espacios abandonados. Tercio Creciente, julio 2021, pp. 137-144, https://dx.doi.org/10.17561/rtc.20.6011

\author{
Ilaria Degradi \\ ilaria.degradi@gmail.com \\ Universidad de Jaén (España)
}

Recibido: 08/01/2021 Revisado: 25/03/2021

Aceptado: 14/06/2021 Publicado: 31/07/2021

\section{Resumen}

Con el presente artículo, se entienden investigar las buenas prácticas de regeneración urbana de comunidades creativas como estrategia alternativa para enfrentarse a la crisis multifactorial que estamos viviendo. La investigación se focaliza en los vacíos urbanos como espacios de oportunidad para la activación de mecanismos de transición hacia una sociedad sostenible y pretende dar visibilidad, conectar e idear escenarios futuros construidos desde abajo a través de procesos participativos e innovadores.

\section{Abstract}

This article investigates the good practices of urban regeneration performed by creative communities as an alternative strategy to face the multifactorial crisis that we are experiencing. The research focuses on empty urban slots as opportunities for the activation of transition mechanisms towards a sustainable society and aims to give visibility, connect and devise future bottom-up scenarios and initiatives built from below through participatory and innovative processes.

\section{Palabras clave}

Espacios en desuso, crisis multifactorial, procesos participativos, regeneración urbana
Keywords

Abandoned places, multifactorial crisis, participatory processes, urban regeneration 


\section{Tercio Creciente}

DOI: https://dx.doi.org/10.17561/rtc.20.6011

Investigación
Maneras de habitar los espacios desde la mirada estética

Introducción

Este artículo se posiciona en el panorama de transición hacia una sociedad sostenible e ilustra algunas posibilidades existentes para enfrentar la actual crisis ecosocial a través de la regeneración urbana. Dada la necesidad de un cambio de paradigma, esta investigación defiende que el uso de diferentes disciplinas artísticas puede representar una solución alternativa para reinterpretar los vacíos urbanos en una clave contemporánea y transformarlos en bienes comunes. Como consecuencia de la multiplicación de estas iniciativas, se considera apropiado crear una red de conexión entre las realidades existentes, capaz de consolidar el movimiento emergente y promover el encuentro y el intercambio de conocimiento entre los proyectos activos.

\section{Tematica}

Esta investigación se focaliza en la reutilización de espacios en desuso como laboratorios sociales donde las comunidades encuentran oportunidades de intercambio y reemplazan la lógica de la competencia a favor de la colaboración, dando lugar a bienes comunes urbanos. Los intersticios de las ciudades se transforman en territorios fértiles (Soto, 2017) para la comunidad donde los ciudadanos son libres de planificar el territorio y auto-construir un entorno basado en sus necesidades personales, estableciendo su propia identidad colectiva y creativa. Este análisis se focaliza en las buenas prácticas de regeneración urbana que fomentan la cultura desde abajo y experimentan una nueva forma de convivencia y gestión horizontal, transformando lugares olvidados en pulmones urbanos donde florece la creatividad y el contacto con la Tierra.

\section{Problemática}

Las ciudades tienen todavía la estructura original con la que fueron concebidas, características del desarrollo industrial y la evolución del capitalismo. La prioridad dada en la planificación territorial al flujo de tráfico, al acceso fluido a los centros comerciales y a la optimización del espacio habitable de las viviendas, tienen graves consecuencias como la creciente contaminación del aire, el incremento exponencial del número de ciudadanos, el progresivo consumo de recursos disponibles y la inevitable reducción de la calidad de vida. Como se destaca en el artículo Hidden public spaces (Fassi, Galluzzo y Rogel: 2016), los términos más frecuentes para describir las realidades urbanas son exclusión social, alienación, segregación y soledad. 


\section{Tercio Creciente}

DOI: https://dx.doi.org/10.17561/rtc.20.6011 Investigación
Maneras de habitar los espacios desde la mirada estética

Julio 2021

Aunque la ciudad se transforma constantemente y la planificación urbana trae cambios importantes en línea con las necesidades de los habitantes, la definición de las necesidades de la población que toman las administraciones en términos sociales, culturales y ambientales sigue siendo cuestionable y el método de imposición desde arriba es evidente.

\section{Movimiento existente}

Somos testigos de un movimiento expandido de resiliencia urbana en el que los habitantes de diferentes ciudades del mundo, impulsados por el deseo de pertenecer a una comunidad y por la necesidad de recuperar el tiempo y el espacio que les ha sido robado, ponen en marcha procesos de colaboración e iniciativas culturales que promueven la innovación social, la creación de comunidad, el consumo local y nuevos modelos económicos, mejorando la calidad de vida y el bienestar de los alrededores. Como señala Manzini (2010), en los últimos años, varios actores sociales han demostrado que pueden actuar fuera de los modelos económicos dominantes. Casos como Cascinet, Isola Pepe Verde, Macao, Cinema Usera, Campo de la Cebada, Esta es una plaza, La Tabacalera, La Casa Invisible, Holzmarkt son solo algunos de los muchos proyectos existentes. Detrás de cada uno de estos casos prometedores hay grupos de personas que inventan, potencian y gestionan soluciones innovadoras creadas a partir de lo que ya existe dando vida a las comunidades creativas (Meroni: 2007; Sánchez-León: 2018; Albelda, Sgaramella y Parreño: 2019; Haxeltine y Seyfang: 2009). De hecho, con Hopkins y Thomas (2016), se verifica que algunas de las características más importantes en las iniciativas de transición son precisamente la creatividad, el diseño y el arte.

\section{La Corriente del Post-degrado}

A partir del año 2012 empecé a visitar e investigar los casos de conversión de áreas abandonadas industriales y rurales con contenidos socioculturales, nombrando esta emergente tendencia de regeneración como La corriente del Post-degrado. Este movimiento comprende todo tipo de reactivación de espacios, abiertos o cubiertos, legales o ilegales, con o sin ánimo de lucro, institucional o amateur. Lo que une a todos estos proyectos es la devolución de nueva vida a un espacio después de una época de abandono. Cambiando el uso o destino de los lugares infrautilizados, se renueva la producción industrial por lo que han sido concebidos hacia una producción de servicios para el tiempo libre y la cultura, reescribiendo sus identidades con un enfoque contemporáneo (Fig.1). 


\section{Tercio Creciente}

DOI: https://dx.doi.org/10.17561/rtc.20.6011 Investigación
Maneras de habitar los espacios desde la mirada estética

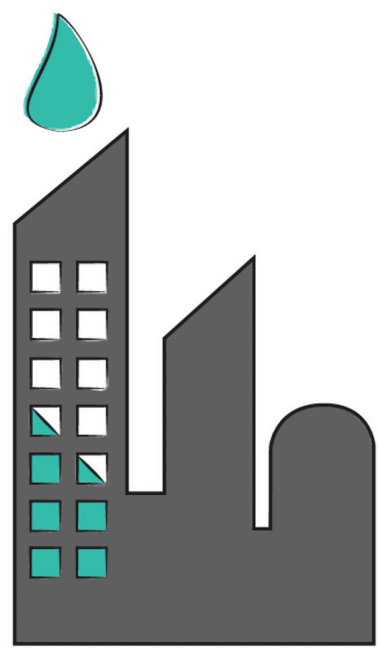

\section{LA CORRENTE DEL POSTDEGRADO}

Figura 1

Este proyecto se basa en la necesidad urgente expresada por la comunidad para enfrentar el cambio. Aunque el movimiento de regeneración territorial es un fenómeno en constante crecimiento, es necesario dar visibilidad, multiplicar y apoyar los proyectos que promueven estas acciones. De ahí la importancia de crear una red que conecte espacios, personas e iniciativas.

Post-degrado es una plataforma online diseñada para dar visibilidad y fomentar la regeneración sociocultural de lugares con encanto arquitectónico, donde revivir la memoria histórica de lo que fue y disfrutar del nuevo uso previsto que se les ha asignado (Degradi: 2020).

Divididos en tres categorías, se ilustran los espacios según su uso original: industrial, rural o ferroviario y, con el uso de iconos, se facilita la comprensión de la nueva función aplicada a los diferentes espacios y de los servicios de los que se puede disfrutar en ellos. De cada proyecto, hasta ahora restringidos a la zona de Milán y en continua expansión a nivel internacional, se aporta una breve descripción que aclara el proceso de transformación del lugar, desde su origen hasta la actualidad y una recopilación de imágenes que ilustra el espíritu y el carácter de las iniciativas. 
Entre los objetivos de este proyecto, destaca la difusión de estas iniciativas y de sus propuestas culturales con el fin de concienciar la comunidad local y forastera sobre la existencia de propuestas para disfrutar del tiempo libre, como alternativas a las prácticas de consumo masificado en los centro comerciales y condensados en los centros de las ciudades. Una de las razones que motivó la creación de esta plataforma es la similitud de experiencias contadas por los visitantes de paso por mi ciudad natal, Milán, que recuerdan casi exclusivamente el color gris y la riqueza económica que conforman la ciudad de la moda. Un prejuicio derivante de la morfología de las calles céntricas del quadrilatero de la moda, famoso en todo el mundo como barrio de lujo donde se encuentran las tiendas y showroom de la moda y del diseño. Sin embargo, afuera de este pequeño y célebre distrito, hay muchas otras zonas verdes, alternativas, poéticas, multiétnicas, industriales, rurales y marginales. En muchas de ellas están naciendo iniciativas locales, socio-culturales y sostenibles que cambian el aspecto de la ciudad y enseñan la autenticidad de sus comunidades.

Proyectos de regeneración urbana que retoman y alargan el ciclo de vida de espacios en desuso de las ciudades a través de procesos participativos y de autoconstrucción para diseñar un hábitat a medida fundado en la creatividad y en la experiencia de su comunidad. El uso de materiales reciclados es un elemento que identifica el aspecto de estos lugares ya que los ciudadanos se basan en las lógicas del DIY (Do It Yourself) para planificar y construir sus espacio con gastos limitados y mucha imaginación, estableciendo la identidad de la comunidad y, en consecuencia, proporcionando un sentido de pertenencia y protección.

Generar un intercambio de información y consejos prácticos entre comunidades activas para orientar y facilitar el proceso de generación de lugares fértiles y de buenas prácticas es otro de los objetivo que se pretenden alcanzar a través de la plataforma del Post-degrado.

Asimismo, para fomentar el movimiento de regeneración de espacios en desuso como laboratorios para la comunidad, el mapa interactivo Los Lugares del Post-degrado se propone visibilizar las áreas que se encuentran actualmente en estado de abandono para señalar, por un lado la extensión del fenómeno y por otro, los posibles espacios de intervención.

Aunque las ciudades parecen estar superpobladas y saturadas, hay una serie de espacios indecisos, sin funciones, en los que es difícil establecer un nombre (Clément: 2005). Terrenos a la espera de un destino, residuos urbanos derivados del abandono de una actividad comercial, antiguas fábricas infrautilizadas y granjas remotas olvidadas son solo algunos de los innumerables vacíos urbanos que permanecen en silencio en nuestras ciudades; áreas ignoradas o, como las define Francesco Careri (2016), amnesias urbanas. Como explica Careri (2006), estos espacios pueden ser reinterpretados, recorridos y líricamente despertados por aquellos poetas, filósofos y artistas capaces de detenerse en lo que no existe para crear algo nuevo. 


\section{Conclusión}

Este proyecto pretende fusionar el arte y el diseño para comunicar de manera efectiva un escenario atractivo capaz de estimular la acción y la participación de múltiples sujetos. En la constante investigación teórico-práctica que alterna el análisis bibliográfico y académico con la acción y la producción, el objetivo es diseñar herramientas creativas para dar visibilidad y valor a las prácticas de regeneración con el fin de crear espacios de oportunidad y posibles escenarios futuros.

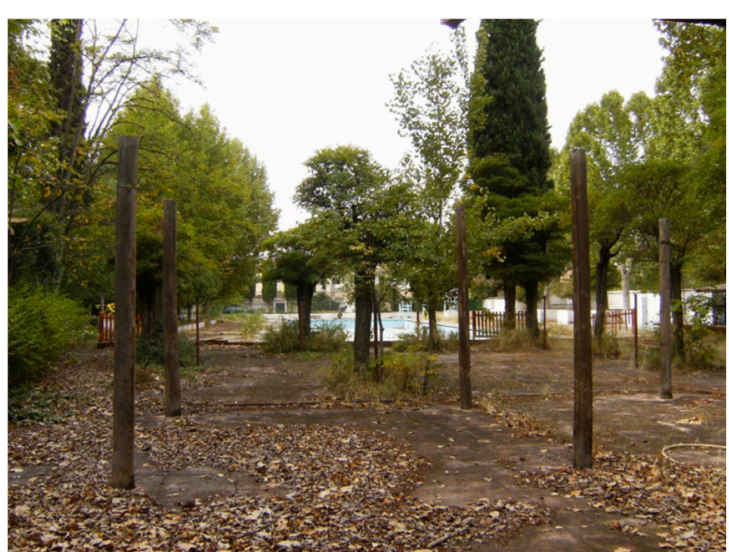

Figura 2

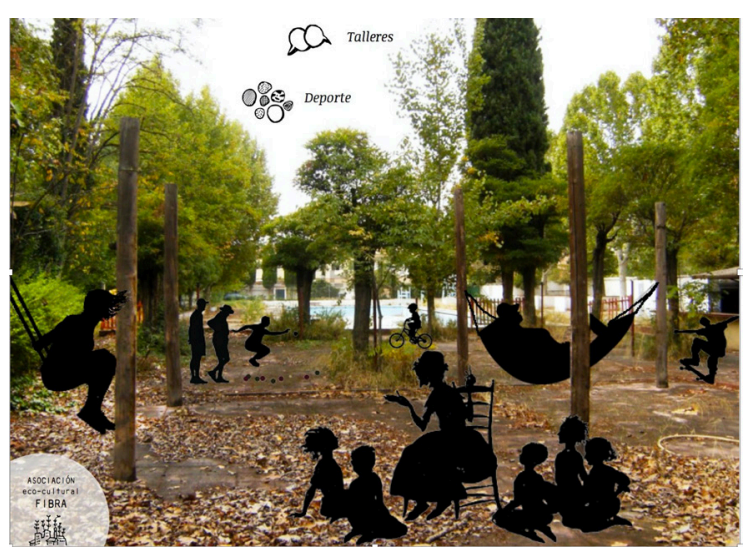

Figura 3

Las figuras 2 y 3 representan uno de los 3 escenarios diseñados en ocasión de nuestro encuentro, como asociación eco-cultural Fibra, con la propietaria de la piscina abandonada Paraíso de Granada, en venta desde hace unos años a precios inaccesibles. No obstante la propietaria que nos acogió apreciò nuestro interés en aquel espacio y la propuesta de devolverle vida con contenidos socio-culturales, finalmente las ideologías de los numerosos herederos de la propiedad resultaron ser muy distintas y, como pasa en muchos otros casos, ralentizan o más bien bloquean cualquier acuerdo entre terratenientes y comunidades limítrofes. La circunstancia por lo que tanto la piscina Paraíso como la multitud de vacíos urbanos siguen a la espera de un comprador y en estado de abandono, anima este proyecto a seguir creando y difundiendo herramientas para demostrar que un espacio recalificado por y para la comunidad, puede generar beneficios también para los propietarios privados o públicos que sean, gracias al incremento del valor social, cultural y territorial que una comunidad es capaz de conseguir.

El movimiento sociocultural de transición hacia la sostenibilidad encuentra oportunidad de existir y desarrollarse en los espacios indecisos y en la aplicación de buenas prácticas de regeneración urbana. Es por ellos que se considera necesario liberar las propiedades privadas en 


\section{Tercio Creciente}

DOI: https://dx.doi.org/10.17561/rtc.20.6011 Investigación

desuso y transformarlas en bienes comunes, facilitar encuentros para promover la visibilidad y el intercambio de conocimiento entre las diferentes experiencias de comunidades creativas y tejer una red entre las realidades activas, contribuyendo a la consolidación de un network de colaboración internacional.

\section{Referencias}

Albelda, José, Parreño, José María, Henriquez J. M. Marrero (2018): Humanidades Ambientales. Pensamiento, arte y relatos para el siglo de la gran prueba. Madrid: Catarata.

Albelda, José, Sgaramella, Chiara y Parreño, José María (2019): Imaginar la transición hacia sociedades sostenibles. València: Editorial Universidad Politècnica de València.

Careri, Francesco (2016): Pasear, detenerse. Barcelona: Gustavo Gili.

Careri, Francesco (2006). Walkscape, camminare come pratica estetica. Torino: Einaudi.

Degradi, Ilaria (2020). Territorios germinados. Un recorrido personal entre buenas prácticas de reactivación sociocultural en espacios abandonados en ENTRE GRIETAS Reflexiones e investigaciones artísticas en el contexto de transición ecosocial. Jaén: AASA.

Fassi Davide, Galluzzo Laura e Rogel Liat (2016): Hidden public spaces, when a university campus becomes a place for communities in 2016 Design Research Society 50th Anniversary Conference. Brighton, UK. https://doi.org/10.21606/drs.2016.377

Gilles, Clément. (2005): Manifesto del Terzo Paesaggio. Macerata: Quodlibet.

Haxeltine, Alex e Seyfang, Gill (2009): Transitions for the People: Theory and Practice of 'Transition' and 'Resilience' in the UK's Transition Movement. Norwich:Tyndall Centre for Climate Change Research.

Hopkins, Rob e Thomas, Michael (2016): The Essential Guide to Doing Transition. Totnes: Transition Network.

Manzini, Ezio (2010), The journal of design strategies. Vol. 4, No. 1. The New School for Design, New York.

Meroni, Anna (2007): Creative communities. People inventing sustainable ways of living. Milano: Edizioni POLI.design. 
Tercio Creciente

ista de Estudios en Sociedad, Artes y

DOI: https://dx.doi.org/10.17561/rtc.20.6011

Maneras de habitar los espacios desde la mirada estética

Julio 2021

Riechmann, J. (2015): Autoconstrucción. La transformación cultural que necesitamos. Madrid: Catarata.

Sánchez-Leon, Nuria (2018): El papel del arte en la transición ecosocial: casos anglosajones y españoles en Humanidades Ambientales. Pensamiento, arte y relatos para el Siglo de La Gran Prueba. Madrid: Catarata. pp. 147-163.

Soto Sánchez, Pilar (2017): Arte, ecología y consciencia. Propuetas artísticas en los márgenes de la política el género y la naturaleza. Tesis Doctoral, Universidad de Granada: Granada.. 